\title{
C. Gassulla d'Ursino, Poesia festiva. Edició i introducció a cura de Vicent Josep Escartí, València, Institució Alfons el Magnànim, 2015, 223 pp.
}

L’edició, filològica o bé modernitzada, de textos manuscrits és, sense cap mena de dubtes, la més indicada per tal de conéixer i per tal d'indagar el nostre passat literari. Hi ha una altra mena d'edicions, les facsímils, per exemple, que ens mostren els documents de primera mà, tal i com si ens els presentaren a la sala de consulta d'un qualsevol arxiu històric. Són edicions destinades potser a bibliògrafs o bé a interessats pel decurs de la cal-ligrafia, els usos escrits, allunyats com estan de la regulació de la impremta. $\mathrm{O}$ bé són edicions il.luminades per a afeccionats al món del llibre, els quals s'entretenen col-leccionant i contemplant aquells manuscrits remots, vertaderes obres d'art en ocasions, grans volums ben ornamentats que passen a ocupar els prestatges més vistosos d'una biblioteca.

Aquesta reflexió inicial no és anodina. Les transcripcions de textos literaris i historiogràfics, amb uns criteris ben estipulats i ben acceptats per tota la comunicació científica són, al meu parer, les més necessàries per tal de conéixer directament un determinat període històric o literari. I juntament amb l'edició, hi cal un complet estudi introductori, el qual contextualitze el lector dins l'època de producció del document, a més d'identificar-li el seu autor o autors, qui van ser i en què es van ocupar. Una introducció amb dades suficients que ens permeta iniciar la nostra lectura des d'uns paràmetres contextuals que ens ajuden a entendre i a sospesar què va motivar aquella obra i quina fou la seua importància, la seua repercussió o la seua aportació en la nostra cultura, en la nostra historiografia o en la nostra literatura.

L'edició que ens ocupa és, precisament, un d'aquests exemples d'investigacions ben elaborades, de transcripcions accessibles i adequades, una publicació que ens rescata de l'oblit quasi absolut un escriptor pràcticament ignot: el lletraferit morellà Carles Gassulla d'Ursino. Vicent Josep Escartí ha ocupat bona part de la seua tasca investigadora en l'edició de textos literaris del període de l'Edat Moderna — un període menystingut per la història de la literatura catalana durant molt de temps, després de l'època d'esplendor del cinc-cents. Gràcies a les seues edicions, investigacions i estudis de tota mena, aquests tres segles que comprenen els nostres usos literaris fins el huitcents - Renaixement, Barroc i Neoclassicisme-, l'Edat Moderna ara mateix ocupa un lloc adequat, tot i que modest, al bell mig de la nostra historiografia literària. I ha relegat per al període altres etiquetes tan injustes com inapropiades i que feren tanta fortuna com fou la de la Decadència.

Fins aquesta publicació, Carles Gassulla d'Ursino era un personatge quasi totalment desconegut per a la història de la literatura. Poeta i dramaturg, va nàixer 
a Morella el 25 de maig de I674, al si d'una família ben acomodada i lletraferida, vinculada al poder municipal, que ell també hi exercí. A més de la informació dels principals bibliògrafs valencians - Josep Rodríguez, Vicent Ximeno o Serrano Morales-, el professor Escartí ha consultat els arxius i els escassos estudis publicats sobre l'autor, per tal de presentar-nos-el com un home d'aspiracions nobiliàries, que visqué els anys convulsos de la Guerra de Successió i que entre tanta maror política sabé situar-se i adaptar-se al seu temps. No debades, Gassulla, considerat en un altre temps borbònic, és reivindicat ara, com a partidari de l'arxiduc Carles — si més no durant un temps-, com ho demostra ben clarament Escartí gràcies a la localització d'unes lloances del poeta morellà a la Casa d'Àustria: «quiere María / dar a la cassa de Austria / triumfos y dichas (...) / para que sus vassallos, / felizes digan: / ¡Viva Carlos Terzero! ¡Mil años viva!».

Com a literat, Carles Gassulla ens deixà una vasta obra, en castellà majoritàriament, però també en català — $\mathrm{i}$ amb incursions en d'altres llengües com ara en francès, portuguès, llatí i italià. Fet que ens demostra la seua excel-lent formació i erudició, i la seua afecció poliglota, molt del gust del Barroc. També treballà tota mena de gèneres: des de la poesia religiosa (lloances, gojos) i profana (lloances civils) a comèdies, traduccions (d'autors clàssics com Cató), discursos, textos per a ser musicats (nadales o villancets), lletres, diàlegs, col-loquis, i un llarg etcètera. L'edició de Vicent-Josep Escartí ens presenta ara les 22 composicions en la nostra llengua que s'han conservat en l'únic manuscrit de l'autor que ens ha pervingut: Elpensil celeste de flores, conservat a l'Arxiu de l'església arxiprestal de Morella. Aquestes peces literàries, segons llegim a la introducció, «estaven concebudes per tal d'inscriure's en un context festiu, més o menys públic, i van des de celebracions locals de relleu, a festes privades d'abast quasi familiar».

Els diàlegs de Gassulla són els textos més reeixits, ja que l'autor s'allunya de les convencions literàries i expressa de primera mà la riquesa cultural pròpia i la de la societat de l'època. Aquests diálogos serijocosos — seguint la seua pròpia denominació- els podem vincular a un altre gènere de gran importància en la nostra tradició literària, com són els col-loquis, representats per actors afeccionats o col-loquiers, davant un públic eminentment popular. Les escenes costumistes, les referències a la vida quotidiana, són mostra de la realitat més immediata, i Carles Gassulla les escrivia i les explicava amb solvència i amb espontaneïtat. És, per tant, també, un enllaç, un punt de trobada entre la tradició anterior — representada per autors com Pere Jacint Morlà- i la posterior: la dels col.loquis, soliloquis i raonaments, tan abundants a partir de la segona meitat del segle XviII. 
En definitiva, cal agrair —en primer terme, al professor Vicent-Josep Escartí, i a la Institució Alfons el Magnànim, en segon— aquesta edició. Posar a l'abast del lector actual l'obra d'un autor, d'un escriptor, d'un temps anterior és una oportunitat única per tal d'endinsar-nos en el nostre passat i la nostra riquesa literària i cultural, i per tal de conèixer-la de primera mà. Les investigacions i les edicions d'Escartí, amb aquest desideràtum, sempre han estat modèliques, i la col-lecció «Biblioteca d'Autors Valencians», amb més de seixanta volums editats, és un autèntic referent. Aquest volum, encara, es completa amb tres apèndixs. Al primer es troba la Loa. La conquista de Morella, que en forma de caballería se dedicó a la Pura Concepción de María, en su día, representada a la capital dels Ports i que enllaça amb un gènere teatral de forta tradició a les Illes Balears i a altres ciutats del País Valencià. També hi trobem la Dedicatòria i el Pròleg al Pensil Celeste de Flores —igualment en castellà- que són un tast de la prosa barroca de l'autor en aquella llengua. El volum es tanca amb un complet glossari que en facilita la lectura.

Ramon Mora i Galbis

Universitat de València elbenicadell@hotmail.com 